\title{
Expression of engrailed homeobox 2 regulates the proliferation, migration and invasion of non-small cell lung cancer cells
}

\author{
XIANGXIAO LIN ${ }^{1 *}$, XINCUN LIU $^{1 *}$ and CUNQI GONG ${ }^{2}$ \\ ${ }^{1}$ Respiratory Department, Affiliated Hospital of Jining Medical University; ${ }^{2}$ Department of Clinical Laboratory, \\ Jining No. 1 People's Hospital, Jining, Shandong 272000, P.R. China
}

Received July 13, 2016; Accepted November 29, 2017

DOI: $10.3892 / \mathrm{ol} .2018 .8693$

\begin{abstract}
The present study aimed to investigate the expression, biological function and mechanism of action of engrailed homeobox 2 (EN2) in non-small cell lung cancer (NSCLC) at the tissue and cellular level. A total of 42 patients who underwent surgical resection of NSCLC tissues between January 2014 and January 2015 were included in the present study. EN2 mRNA expression levels in explanted NSCLC tissues were determined using reverse-transcription quantitative polymerase chain reaction analysis. Adenocarcinoma human alveolar basal epithelial A549 cells were transfected with negative control plasmids or those containing EN2, enabling its overexpression. To assess the effect of EN2 overexpression in A549 cells, a Cell Counting kit-8 assay was used to analyze cellular proliferation, a Transwell assay was used to evaluate cellular migration and invasion and flow cytometry was used to detect the cell cycle distribution. To measure protein expression of EN2 and $\beta$-catenin in A549 cells, western blotting was also conducted. EN2 mRNA expression levels in NSCLC tissues were lower than those in normal tissues, and were associated with metastasis, clinical staging and differentiation degrees of NSCLC. Increased expression of EN2 inhibited the proliferation of A549 cells in vitro, and suppressed their migration and invasion. Elevated EN2 expression inhibited the proliferation of A549 cells by regulating the $G_{1} / S$ phase transition. $\beta$-catenin protein expression levels and nuclear translocation in A549 cells were inhibited by EN2 overexpression. The present study demonstrated that expression of EN2 in NSCLC tissues was downregulated and negatively associated with the degree of disease differentiation, lymphatic metastasis and clinical
\end{abstract}

Correspondence to: Dr Cunqi Gong, Department of Clinical Laboratory, Jining No. 1 People's Hospital, 6 Jiankang Road, Jining, Shandong 272000, P.R. China

E-mail: biq000@126.com

*Contributed equally

Key words: engrailed homeobox 2, non-small cell lung cancer, A549 cells, $\beta$-catenin staging. Overexpression of EN2 inhibits the proliferation, migration and invasion of A549 cells, as well as the expression of $\beta$-Catenin and nuclear translocation.

\section{Introduction}

The incidence and mortality of lung cancer is the highest among all malignant tumors worldwide; it is a disease that severely threatens human health and affects quality of life $(1,2)$. Non-small cell lung cancer (NSCLC) accounts for $\sim 80 \%$ of all lung cancer cases. The efficacy of surgical resection, adjuvant radiochemotherapy, immunotherapy and individualized targeted therapy have improved in recent years; however, the 5-year survival rate of NSCLC patients remains $\sim 15 \%$ (3). The occurrence and development of lung cancer is closely associated with the biological behavior of lung cancer cells, although the molecular mechanism that drives the disease remains unclear (4-6). It is widely accepted that the proliferation, invasion and metastasis of tumor cells, and the alteration of intrinsic cellular processes such as apoptosis and the cell cycle, promotes the occurrence and development of NSCLC $(7,8)$. The molecular regulatory mechanism of the biological behavior of lung cancer cells is extremely complex. Therefore, identification of and screening for tumor-associated genes, together with the study of their molecular mechanisms, have considerable clinical value in the diagnosis and treatment of NSCLC.

Homeobox-containing genes are highly evolutionarily conserved; proteins encoded by homeobox-containing genes are important transcription factors that precisely regulate the differentiation of cells by specifically activating downstream genes $(9,10)$. Studies have indicated that homeobox-containing genes serve key roles in the generation and differentiation of embryos and organs of organisms. In addition, homeobox-containing genes are important for the regulation of the development and differentiation of adult tissues (11). In recent years, numerous studies have confirmed that HOX genes, a subclass of homeobox-containing genes, also perform important biological functions in the occurrence and development of a variety of tumors $(12,13)$. For example, Zhong et al (14) reported that the methylation of the HOXD13 gene is an important marker in the early diagnosis of breast cancer (14). In addition, Aquino et al (15) revealed that 13 homeobox-containing genes exhibit 
abnormal expression in oral squamous cell carcinoma (15). The members of homeobox-containing genes are numerous and have complex structures. Their functions and molecular mechanisms of action in tumors require further investigation. The engrailed homeobox (EN) family of genes includes EN1 and EN2. EN2 has been reported to serve an important role in the development of embryos and the nervous system (16). It has been demonstrated that EN2 is abnormally expressed in prostate, breast and bladder cancer, and is closely associated with the procession of tumors $(17,18)$. However, the expression level and role of EN2 in NSCLC remains unclear. In the present study, the expression and mechanism of action of EN2 in NSCLC was investigated using reverse transcription-quantitative polymerase chain reaction (RT-qPCR), western blot analysis, and a Transwell assay. The present study provided an experimental basis for screening biological targets for the diagnosis and treatment of NSCLC.

\section{Materials and methods}

Patients. A total of 42 patients (31 males and 11 females) who received surgical resection of NSCLC tissues between January 2014 and January 2015 were included in the present study. All patients were clearly diagnosed with NSCLC by pathologists. NSCLC and tumor-adjacent normal tissues were collected from all NSCLC patients. The age range of the patients was 27-65 years and the mean age was $41.7 \pm 2.4$ years. Patients were included if they were without: Any other tumors; a long history of drug intake; autoimmune diseases; and adjuvant therapy prior to surgery. Among the 42 patients, 25 had lymphatic metastasis and 17 did not. The Tumor-Node-Metastasis (TNM) staging followed NSCLC TNM staging criteria of American Joint Committee on Cancer 2003 edition (19). Of the 42 patients, 11 had stage I disease, 18 had stage II disease and 13 had stage III disease. All procedures were approved by the ethics committee of Jining No. 1 People's Hospital (Jining, China). Written informed consent was obtained from all patients or their families.

Cells and transfection. The lung cancer A549 cell line was purchased from the Type Culture Collection Chinese Academy of Sciences (Shanghai, China). A549 cells were defrosted at $37^{\circ} \mathrm{C}$ and cultured in $10 \mathrm{ml}$ fresh Dulbecco's Modified Eagle's Medium (DMEM; Hyclone; GE Healthcare Life Sciences, Logan, UT, USA) medium at $37^{\circ} \mathrm{C}$ and $5 \% \mathrm{CO}_{2}$ for $24 \mathrm{~h}$. The old medium was discarded; $5 \mathrm{ml}$ fresh high-glucose DMEM medium supplemented with $10 \%$ fetal bovine serum was added (Hyclone; GE Healthcare Life Sciences). The medium was changed every 2 days and the cells were passaged at $90 \%$ confluence.

A549 cells were cultured in DMEM medium and divided into negative control (NC) and pcDNA-3.1-EN2 groups. At $70-90 \%$ confluence, $0.5 \mu \mathrm{g}$ NC or pcDNA-3.1-EN2 plasmids (Hanbio Biotechnology Co., Ltd., Shanghai, China) were mixed with $1 \mu$ l Lipofectamine ${ }^{\circledR} 2000$ (Invitrogen; Thermo Fisher Scientific, Inc., Waltham, MA, USA), and the mixture was added into two individual vials containing $50 \mu \mathrm{l}$ OptiMemi medium (Hyclone; GE Healthcare Life Sciences). After 5 min, the liquids in the two vials were mixed prior to standing for another $15 \mathrm{~min}$. Next, the mixture was added to the cells, which were incubated for $6 \mathrm{~h}$. Following replacement of the DMEM medium supplemented with $10 \%$ fetal bovine serum, the cells were cultured under normal conditions for $48 \mathrm{~h}$ prior to use.

$R T$-qPCR. Tissues (100 mg) were ground into powder following freezing with liquid nitrogen prior to the addition of $1 \mathrm{ml} \mathrm{TRIzol}$ (Thermo Fisher Scientific, Inc.) for lysis. Subsequently, total RNA was extracted using phenol chloroform method (20). The purity of RNA was determined at $\mathrm{A}_{260} / \mathrm{A}_{280}$ using ultraviolet spectrophotometry (Nanodrop ND1000, Thermo Fisher Scientific, Inc., Wilmington, DE, USA). Next, cDNA was obtained by RT using a PrimeScript RT reagent kit (Takara Biotechnology Co., Ltd., Dalian, China) from $1 \mu \mathrm{g}$ RNA and stored at $-20^{\circ} \mathrm{C}$. The RT reaction system RNA constituted $5 \mu$ l RNA template, $2 \mu$ l Oligo

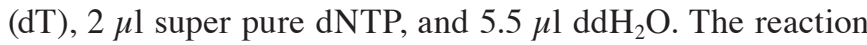
system was first heated to $70^{\circ} \mathrm{C}$ and then kept on ice for $2 \mathrm{~min}$. Following centrifugation at $1,000 \mathrm{x} \mathrm{g}$ at $4^{\circ} \mathrm{C}$ for $30 \mathrm{sec}, 4 \mu \mathrm{l}$ $5 \mathrm{X}$ first-strand buffer and $0.5 \mu \mathrm{l}$ RNasin (Tiangen Biotech Co., Ltd., Beijing, China) were added, followed by addition of $1 \mu 1$ TIANScript M-MLV (Tiangen Biotech Co., Ltd.). The mixture was then incubated at $25^{\circ} \mathrm{C}$ for $10 \mathrm{~min}$ and $42^{\circ} \mathrm{C}$ for $50 \mathrm{~min}$; at $95^{\circ} \mathrm{C}$ for $5 \mathrm{~min}$ the stop reaction was conducted. Subsequently, the samples were kept on ice and $5 \mu \mathrm{l}$ was used for RT-qPCR.

To determine the expression of EN2 in tumor and tumor-adjacent tissues, the Quant One Step qRT-PCR (SYBR-Green) kit (Tiangen Biotech Co., Ltd.) was used, with GAPDH serving as the internal reference. The RT-qPCR reaction system $(30 \mu 1)$ contained $5 \mu \mathrm{l}$ cDNA, $10 \mu \mathrm{l}$ mix, $1 \mu 1$ upstream primer, $1 \mu 1$ downstream primer, and $13 \mu 1$ $\mathrm{ddH}_{2} \mathrm{O}$. The primers used were: EN2 forward, 5'-CTACTG TACGCGCTACTCGG-3' and reverse, 5'-CCCGTGGCC TTCTTGATCTT-3'; GAPDH forward, 5'-AGGTGAAGG TCGGAGTCAAC-3' and reverse, 5'-CGCTCCTGGAAG ATGGTGAT-3'. The PCR protocol was as follows: Initial denaturation at $95^{\circ} \mathrm{C}$ for $10 \mathrm{~min} ; 40$ cycles of denaturation at $95^{\circ} \mathrm{C}$ for $30 \mathrm{sec}$ and annealing at $60^{\circ} \mathrm{C}$ for $30 \mathrm{sec}$ (iQ5; Bio-Rad Laboratories, Inc., Hercules, CA, USA). The $2^{-\Delta \Delta C q}$ method (21) was used to calculate the relative expression of EN2 mRNA against GAPDH; each sample was tested in triplicate.

Cell Counting kit-8 (CCK-8) assay. For the growth curve assay, A549 cells were seeded into 96-well plates at a density of 5,000 cells per well in triplicate. Every $24 \mathrm{~h}$, the cells were incubated with CCK-8 reagent (Beyotime Institute of Biotechnology, Shanghai, China) at $37^{\circ} \mathrm{C}$ for $30 \mathrm{~min}$. Absorbance at $490 \mathrm{~nm}$ was read on a microplate reader (168-1,000; Model 680, Bio-Rad Laboratories, Inc.) at 24, 48 and $72 \mathrm{~h}$, and proliferation curves were plotted using absorbance values at each time point.

Transwell assay. Transwell chambers $(8 \mu \mathrm{m}$ diameter and 24 wells; Corning Inc., Corning, NY, USA) were used to evaluate the migration ability of A549 cells. Transfected cells were collected by trypsin digestion and resuspended 
to a density of $2 \times 10^{5}$ cells $/ \mathrm{ml}$ using serum-free DMEM. The cell suspension (200 $\mu 1$ per well) was added into the upper chamber. In the lower chamber, $500 \mu 1$ DMEM medium supplemented with $10 \%$ fetal bovine serum was added. Following incubation for $24 \mathrm{~h}$, cells in the upper chamber were removed with a cotton swab. Next, the chamber was fixed using $4 \%$ formaldehyde for $10 \mathrm{~min}$ at room temperature and then subjected to Giemsa staining at room temperature for $1 \mathrm{~min}$. Following three washes of the cells that migrated to the other side of the chamber with phosphate-buffered saline (PBS), these cells were counted in 5 individual fields under a light microscope (magnification, x200) to evaluate migration ability.

Matrigel invasion chambers (BD Biosciences, Franklin Lakes, NJ, USA) were used to determine the invasive ability of cells. Matrigel was first diluted with serum-free DMEM medium at a ratio of 1:2. In the upper chamber, $50 \mu 1$ diluted Matrigel was added and maintained at $37^{\circ} \mathrm{C}$ for $1 \mathrm{~h}$. In the lower chamber, $500 \mu \mathrm{l}$ DMEM medium supplemented with $10 \%$ fetal bovine serum was added. Following incubation at $37^{\circ} \mathrm{C}$ for $24 \mathrm{~h}$, the cells $\left(1 \times 10^{5}\right)$ in upper chamber were removed with a cotton swab. Next, cells in the chamber was fixed using $4 \%$ formaldehyde for $10 \mathrm{~min}$ at room temperature and then subjected to Giemsa staining at room temperature for $1 \mathrm{~min}$. Following three washes of the cells that moved to the other side of the chamber with PBS, these cells in five fields were counted under a light microscope (magnification, x200) to evaluate invasion ability.

Flow cytometry. At $24 \mathrm{~h}$ post-transfection, $1 \times 10^{6}$ cells of each group were washed twice with precooled PBS. A Cell Cycle Assay kit (BD Biosciences) was used to determine the cell cycle according to the manufacturer's protocols. The cells were incubated at room temperature with $200 \mu 1$ liquid A for $10 \mathrm{~min}$, and $150 \mu \mathrm{l}$ liquid B for another $10 \mathrm{~min}$. Then, the cells were incubated at room temperature with $120 \mu \mathrm{l}$ liquid $\mathrm{C}$ in the dark for 10 min prior to flow cytometry analysis using FACSVerse $^{\mathrm{TM}}$ flow cytometer (BD Biosciences). The results were analyzed using ModFit software version 3.2 (Verity Software House, Inc., Topsham, ME, USA).

Western blotting. At $48 \mathrm{~h}$ after transfection, A549 cells were trypsinized and collected. Then, precooled radioimmunoprecipitation assay lysis buffer $(600 \mu 1$; $50 \mathrm{mM}$ Tris-base, $1 \mathrm{mM}$ EDTA, $150 \mathrm{mM} \mathrm{NaCl}, 0.1 \%$ SDS, $1 \%$ Triton X-100, and $1 \%$ sodium deoxycholate; Beyotime Institute of Biotechnology) and phenylmethylsulfonyl fluoride were added to the samples. Following lysis for $5 \mathrm{~min}$ on ice, the mixture was centrifuged at $12,000 \mathrm{x}$ g and $4^{\circ} \mathrm{C}$ for $10 \mathrm{~min}$. Protein samples (50 $\mu \mathrm{g}$ per lane) were then mixed with equal volume of $2 \mathrm{X}$ SDS loading buffer prior to denaturation in boiling water bath for $10 \mathrm{~min}$. Subsequently, the samples $(5 \mu \mathrm{l})$ were subject to $10 \%$ SDS-PAGE at $100 \mathrm{~V}$. The resolved proteins were transferred to polyvinylidene difluoride membranes on ice (300 mA, 2 h) and blocked with $50 \mathrm{~g} / 1$ skimmed milk at room temperature for $1 \mathrm{~h}$. Next, the membranes were incubated with rabbit anti-human EN2 polyclonal primary antibody (1:1,000; cat. no. ab28731; Abcam, Cambridge, UK) and rabbit anti-human GAPDH primary antibody $(1: 5,000$; cat. no. ab9485; Abcam) at $4^{\circ} \mathrm{C}$ overnight. Following five washes with PBS with $0.1 \%$ Tween-20 for $5 \mathrm{~min}$, the membranes were incubated with goat anti-mouse $(1: 5,000$; cat. no. ab6789) and goat anti-rabbit (1:2,000; cat. no. ab205718; both Abcam) horseradish peroxidase-conjugated secondary antibodies, respectively, for $1 \mathrm{~h}$ at room temperature prior to five washes with PBS with Tween-20 for $5 \mathrm{~min}$. Next, the membrane was developed with an enhanced chemiluminescence detection kit (Sigma-Aldrich; Merck KGaA, Darmstadt, Germany) for imaging. Image lab v3.0 software (Bio-Rad Laboratories, Inc.) was used to acquire and analyze imaging signals. The relative content of EN2 protein was expressed as the EN2/GAPDH ratio. For the measurement of relative $\beta$-Catenin expression, polyclonal rabbit anti-human $\beta$-Catenin primary antibody (1:1,000; cat. no. AF0066) and polyclonal rabbit anti-human $\mathrm{H} 3$ histone primary antibody (1:3,000; cat. no. AF0009; both Beyotime Institute of Biotechnology) were incubated according to the western blotting protocol used for EN2, and $\mathrm{H} 3$ histone was used as internal reference.

Statistical analysis. The results were analyzed using SPSS 16.0 statistical software (SPSS, Inc., Chicago, IL, USA). Each test was performed in triplicate. All measurement data were expressed as the mean \pm standard deviation. Data were tested for normality; comparisons between two groups were performed using paired t-test. Multigroup measurement data were analyzed using one-way analysis of variance. In case of homogeneity of variance, the least significant difference and Student-Newman-Keuls post hoc methods were used; in case of heterogeneity of variance, Tamhane's T2 or Dunnett's T3 post hoc methods were used. $\mathrm{P}<0.05$ was considered to indicate a statistically significant difference.

\section{Results}

EN2 mRNA expression levels in NSCLC tissues are lower than those in normal tissues and are associated with the metastasis, clinical staging and differentiation degrees of NSCLC. To measure the expression levels of EN2 mRNA in NSCLC tissues, RT-qPCR was utilized. EN2 mRNA expression levels in NSCLC tissues were significantly lower than those in tumor-adjacent tissues (Fig. 1A). In addition, the expression levels of EN2 mRNA in patients with lymphatic metastasis were significantly lower than those in patients without lymphatic metastasis (Fig. 1B). When assessing the association between E2 expression and clinicopathological characteristics, EN2 expression gradually decreased with the increases in TNM staging (Fig. 1C) and differentiation degrees (Fig. 1D). The results indicated that EN2 mRNA expression levels in NSCLC tissues were lower than those in normal tissues and may be associated with the metastasis, clinical staging and the degree of differentiation of NSCLC.

Increased expression of EN2 inhibits the proliferation of A549 cells in vitro. To investigate the effect of EN2 on the proliferation of A549 cells, a CCK-8 assay was performed. The data revealed that the absorbance of cells transfected with pcDNA-3.1-EN2 was significantly lower than that of cells in NC group at 48 and $72 \mathrm{~h}$ (Fig. 2), indicative of a reduced cellular proliferation. The 
A

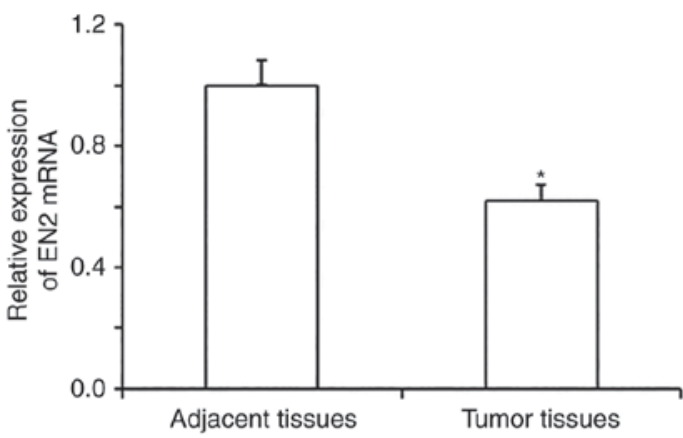

B

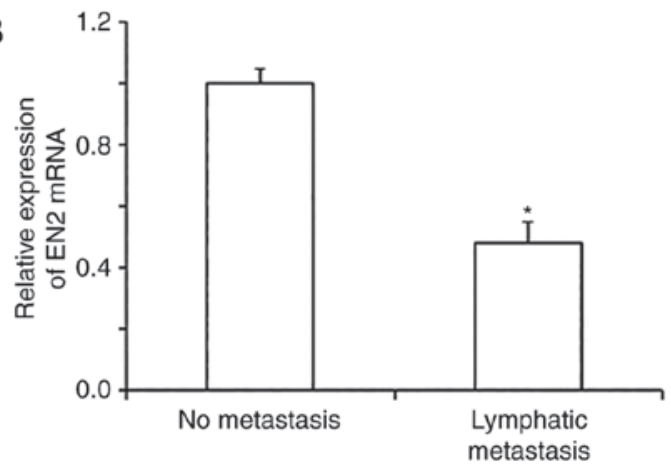

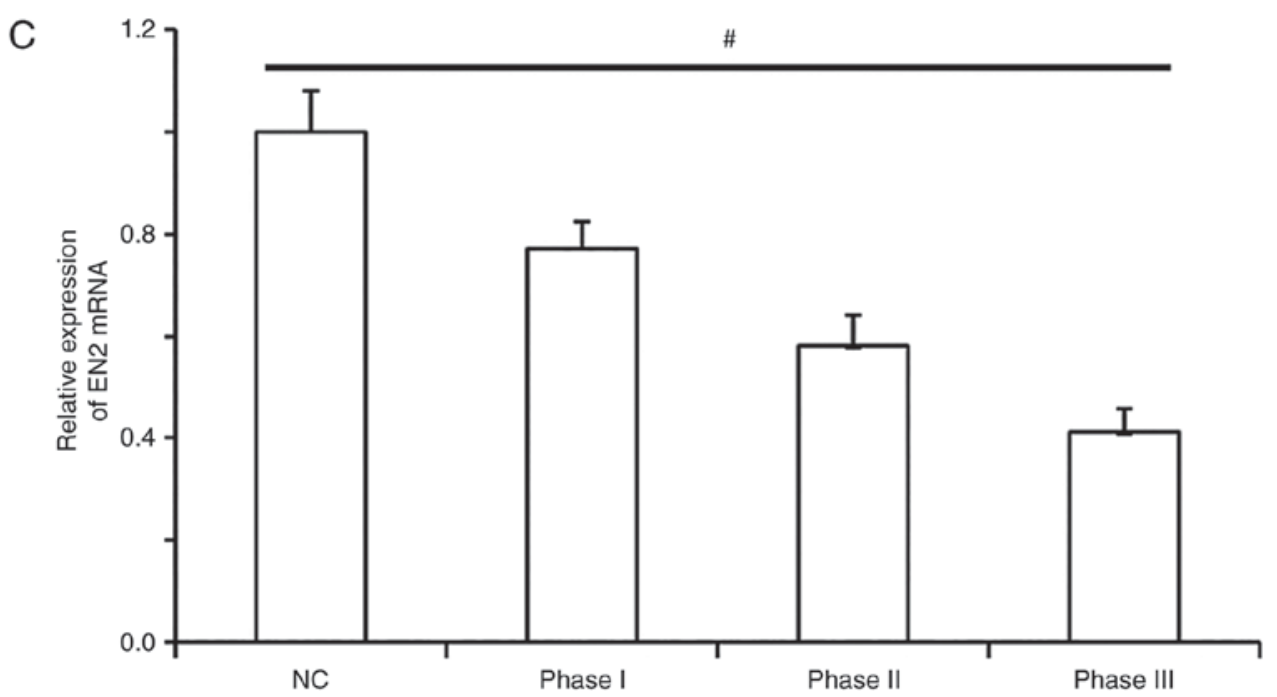

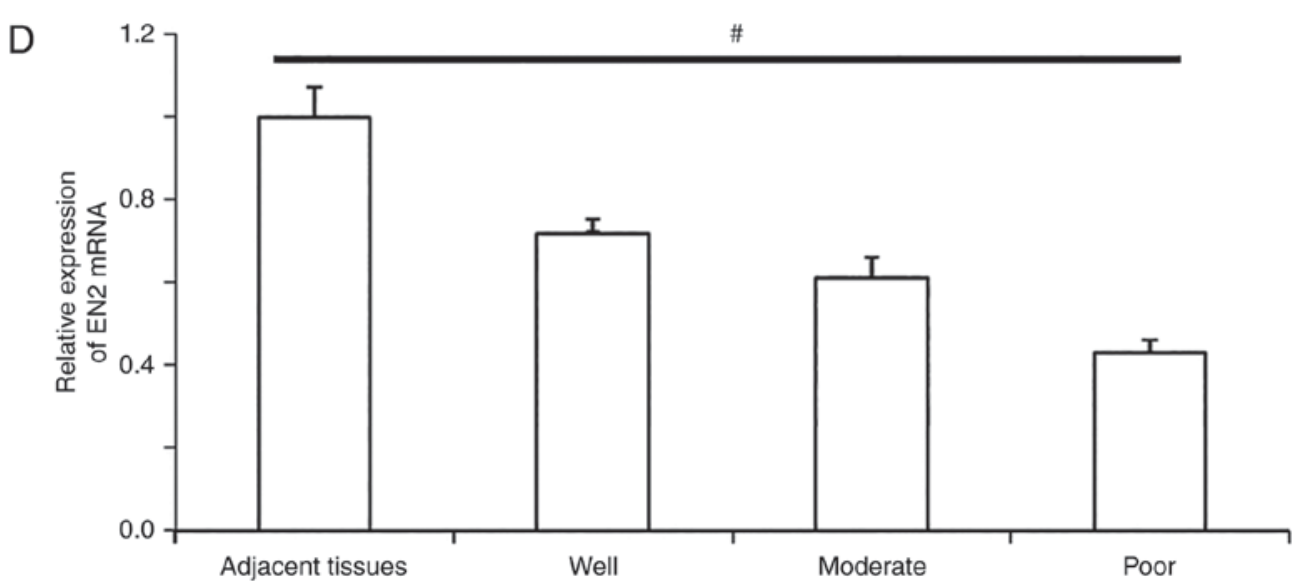

Figure 1. Relative expression of EN2 mRNA in (A) NSCLC tissues and adjacent tissues, (B) patients with or without lymphatic metastasis, (C) patients at different Tumor-Node-Metastasis stages and (D) patients with different degrees of disease differentiation. ${ }^{*} \mathrm{P}<0.05$ compared with the control group; ${ }^{*} \mathrm{P}<0.05$ between any two groups (each group was significantly different from the others). EN2, engrailed homeobox 2; NC, negative control.

results indicated that increased expression of EN2 inhibited the proliferation of A549 cells in vitro.

Overexpression of EN2 suppresses the migration and invasion of A549 cells. To study the migration and invasive abilities of A549 cells, a Transwell assay was performed. Transwell migration and invasion assays demonstrated that the number of A549 cells transfected with pcDNA-3.1-EN2 that crossed the membrane was lower than the number of cells in the negative control group (Fig. 3). These results indicated that the overexpression of EN2 may suppress the migration and invasion of A549 cells.
Elevated EN2 expression inhibits the proliferation of A549 cells by regulating the $G_{I} / S$ phase transition. To investigate the effect of EN2 on the A549 cell cycle, flow cytometry was conducted. The data revealed that A549 cells overexpressing EN2 exhibited $\mathrm{G}_{1} / \mathrm{S}$ phase arrest, unlike the negative control cells (Fig. 4). The results indicated that elevated EN2 expression might inhibit the proliferation of A549 cells by regulating $\mathrm{G}_{1} / \mathrm{S}$ phase transition.

$\beta$-catenin protein expression and nuclear translocation in A549 cells are inhibited by EN2 overexpression. To determine protein expression in A549 cells, western blotting was 


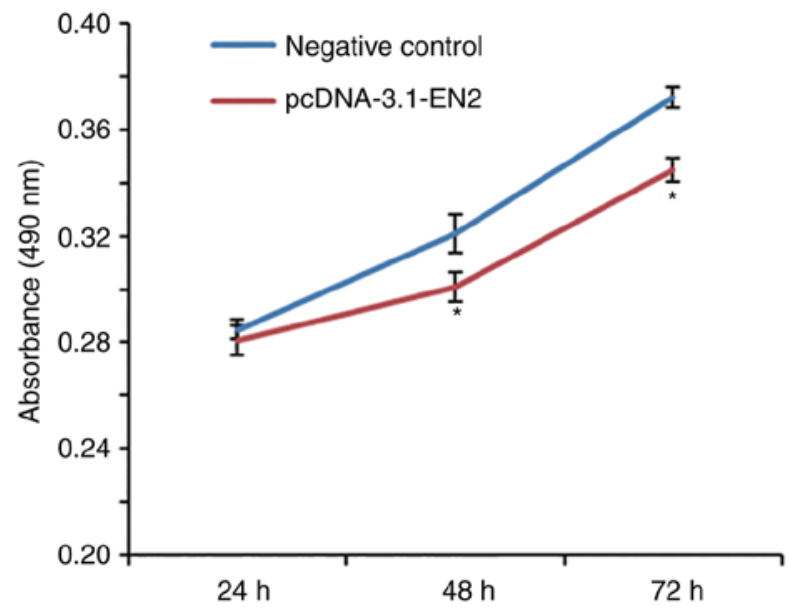

Figure 2. Effect of EN2 overexpression on the proliferation of A549 cells. CCK-8 assay was used to detect cell proliferation. Absorbance at $490 \mathrm{~nm}$ was read on a reader at 24,48 , and $72 \mathrm{~h}$, and proliferation curves were plotted using absorbance values at each time point. ${ }^{*} \mathrm{P}<0.05$ compared with the negative control. EN2, engrailed homeobox 2.
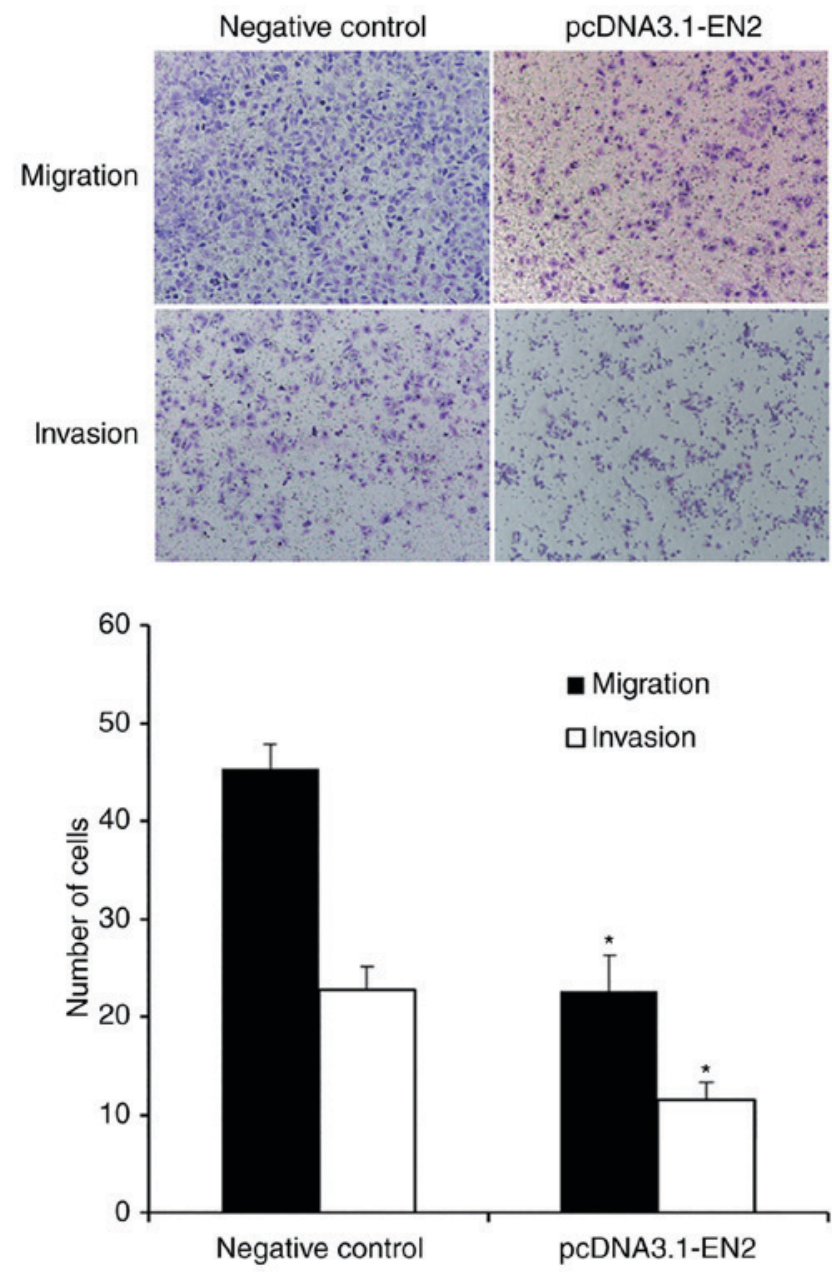

Figure 3. Effect of EN2 expression on the migration and invasive abilities of A549 cells. A transwell assay was used to determine migration and invasion. ${ }^{*} \mathrm{P}<0.05$ compared with the negative control. EN2, engrailed homeobox 2 .

conducted. Following transfection with the pcDNA3.1-EN2 plasmid, EN2 protein expression levels in A549 cells were
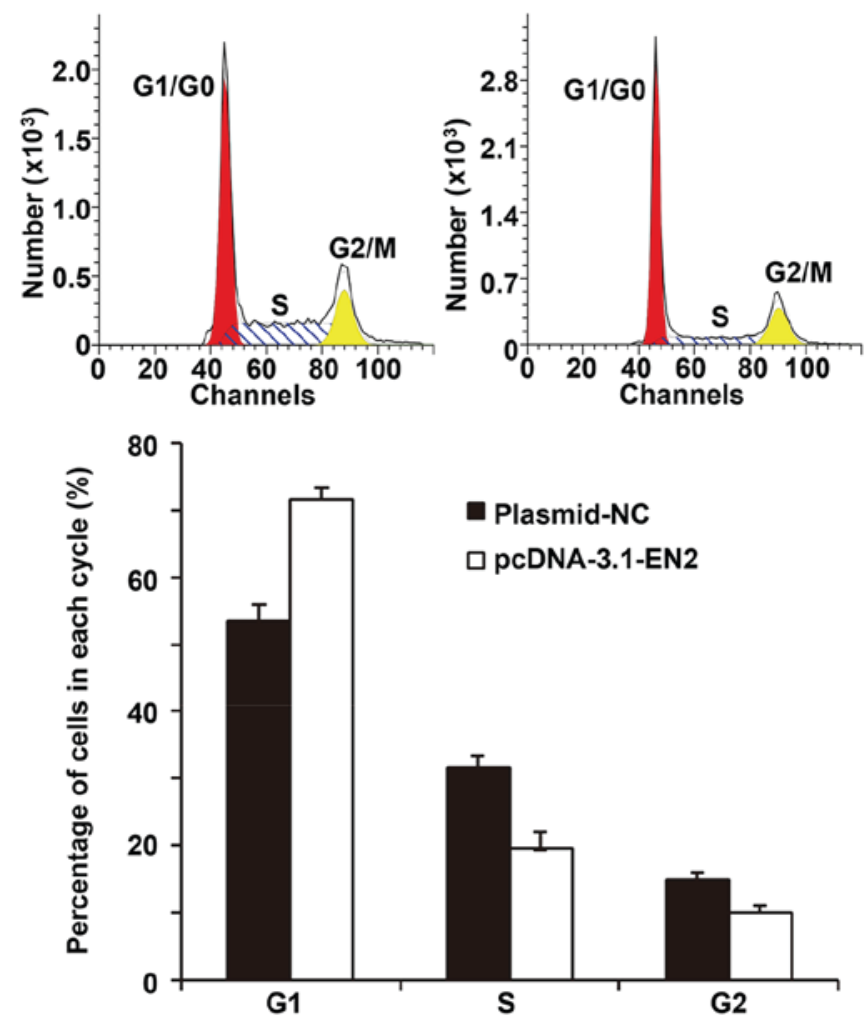

Figure 4. Effect of EN2 expression on A549 cell cycle. Flow cytometry was used to detect the proportion of cells in different locations within the cell cycle. The percentages of cells in $\mathrm{G}_{1}, \mathrm{~S}$ and $\mathrm{G}_{2}$ phases were calculated. EN2, engrailed homeobox $2 ; \mathrm{NC}$, negative control.

significantly enhanced. In addition, $\beta$-catenin protein expression levels were downregulated as EN2 expression levels increased (Fig. 5). The results indicated that $\beta$-catenin protein expression levels and nuclear translocation in A549 cells might be inhibited by EN2 overexpression.

\section{Discussion}

The results of the present study demonstrated that EN2 may act as a tumor-suppressor gene in NSCLC and that reduced expression of EN2 may be closely associated with the occurrence and development of NSCLC. It has been reported that EN2 may serve a notable role in the early development of embryos and the maintenance of the function of nervous system, and is closely associated with the development of the nervous system and autism (22). EN2 has also been demonstrated to be closely associated with the occurrence and development of tumors, potentially acting as a tumor-suppressor gene in certain types of cancer. Martin et al (23) reported that the expression of EN2 in breast cancer cells was upregulated and might have promoted the proliferation of tumor cells. Bose et al (24) revealed that EN2 expression levels were upregulated in prostate cancer cell lines and that the silencing of EN2 expression may inhibit the proliferation of prostate cancer cells via the downregulation of PAX2 gene expression. Morgan et al (25) demonstrated that EN2 content in urine from bladder cancer patients was elevated to levels that were of clinical diagnostic value. In addition, Lai et al (26) reported that EN2 expression was 

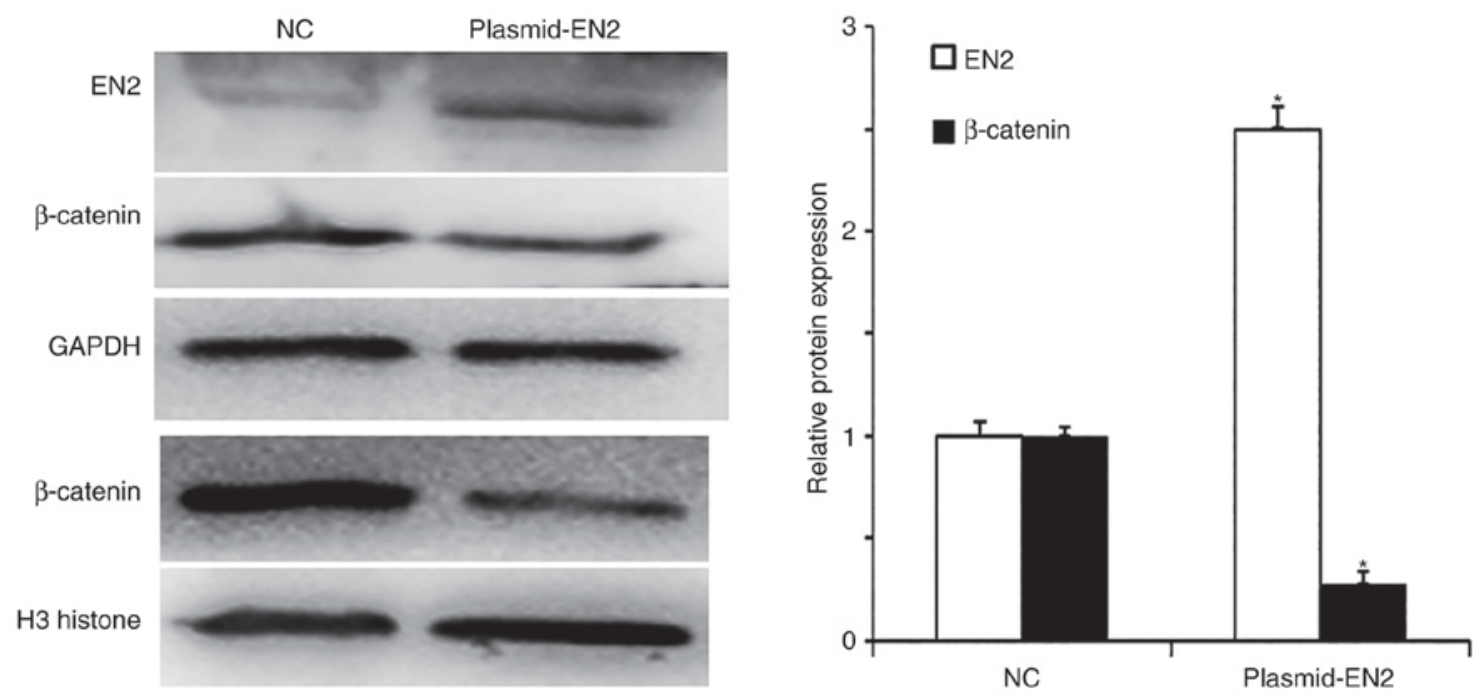

Figure 5. Effect of overexpression of EN2 on $\beta$-catenin protein expression levels and nuclear translocation. Western blotting was used to determine protein expression. " $\mathrm{P}<0.05$ compared with $\mathrm{NC}$ group. EN2, engrailed homeobox 2; NC, negative control.

downregulated in renal clear cell carcinoma and was negatively associated with clinicopathological staging, further indicating that EN2 may be a tumor-suppressor gene. These studies indicated that the biological functions of EN2 might be distinct in different types of tumors.

At present, there is one report on EN2 expression in NSCLC (27). The results of the present study revealed that EN2 expression levels were downregulated in NSCLC, and were negatively associated with lymphatic metastasis, degree of differentiation and TNM staging, indicating that EN2 may have tumor-suppressor gene functions in NSCLC. In vitro experiments demonstrated that the overexpression of EN2 in A549 cells might inhibit the proliferation, migration and invasion of A549 cells. Flow cytometry conducted in the present study revealed that EN2 inhibited the $\mathrm{G}_{1} / \mathrm{S}$ transition of A549 cells, indicating that the downregulation of EN2 facilitates the occurrence and development of NSCLC.

The Wnt signaling pathway is closely associated with cell proliferation, differentiation, migration and invasion. As a key protein in the Wnt signaling pathway, $\beta$-catenin aggregates in the cytoplasm, enters the cell nucleus, exerts its function as a transcription factor and activates the transcription and expression of downstream genes (28). In addition, $\beta$-catenin can also bind with epithelial marker E-cadherin and mediate the migration of cells (29). Western blotting data reported in the present study demonstrated that EN2 overexpression led to the downregulation of $\beta$-catenin protein expression levels in A549 cells; $\beta$-catenin expression levels in the nucleus were significantly reduced, indicating that the upregulation of EN2 may inhibit the activity of the Wnt signaling pathway, in addition to the migration and invasion of A549 cells.

In conclusion, the present study demonstrated that downregulatedEN2 expression might be closely associated with the occurrence and development of NSCLC. Overexpression of EN2 may inhibit the proliferation, migration and invasion of NSCLC, possibly due to the inhibition of Wnt signaling pathway by EN2. Therefore, EN2 has to potential to be considered to be a potential diagnostic marker and therapeutic target for NSCLC.

\section{Acknowledgements}

The authors would like to thank Dr Cheng Zhang of the Affiliated Hospital of Jining Medical University (Jining, China) for their instructions.

\section{Funding}

No funding was received.

\section{Availability of data and materials}

The datasets used and/or analyzed during the current study are available from the corresponding author on reasonable request.

\section{Authors' contributions}

XXL, XCL and CQG designed the study; XXL and XCL performed the experiments; XXL, XCL and CQG analyzed the data. All authors collaborated to interpret results and develop the manuscript. The final version of the manuscript has been read and approved by all authors.

\section{Ethics approval and consent to participate}

All procedures were approved by the ethics committee of Jining No. 1 People's Hospital (Jining, China). Written informed consent was obtained from all patients or their families.

\section{Consent for publication}

Written informed consent was obtained from all patients or their families.

\section{Competing interests}

The authors declare that they have no competing interests. 


\section{References}

1. Zhang YZ, Chen X, Fan XX, He JX, Huang J, Xiao DK, Zhou YL, Zheng SY, Xu JH, Yao XJ, et al: Compound library screening identified cardiac glycoside digitoxin as an effective growth inhibitor of gefitinib-resistant non-small cell lung cancer via downregulation of $\alpha$-tubulin and inhibition of microtubule formation. Molecules 21: 374, 2016.

2. Zheng $\mathrm{H}$, Wang $\mathrm{M}$, Wu J, Wang ZM, Nan HJ and Sun $\mathrm{H}$ : Inhibition of mTOR enhances radiosensitivity of lung cancer cells and protects normal lung cells against radiation. Biochem Cell Biol 94: 213-220, 2016.

3. Trinidad López C, Souto Bayarri M, Oca Pernas R, Delgado Sánchez-Gracián C, González Vázquez M, Vaamonde Liste A, Tardáguila De La Fuente G and De La Fuente Aguado J: Characteristics of computed tomography perfusion parameters in non-small-cell-lung-cancer and its relationship to histology, size, stage an treatment response. Clin Imaging 50: 5-12, 2017.

4. Wei H, Su M, Lin R, Li H and Zou C: Prognostic factors analysis in EGFR mutation-positive non-small cell lung cancer with brain metastases treated with whole brain-radiotherapy and EGFR-tyrosine kinase inhibitors. Oncol Lett 11: 2249-2254, 2016.

5. Zhao T, Gao Z, Wu W, He W and Yang YI: Effect of synchronous solitary bone metastasectomy and lung cancer resection on non-small cell lung cancer patients. Oncol Lett 11: 2266-2270, 2016.

6. Lee P, Leung CC, Restrepo MI, Takahashi K, Song Y and Porcel JM: Year in review 2015: Lung cancer, pleural diseases, respiratory infections, bronchiectasis and tuberculosis, bronchoscopic intervention and imaging. Respirology 21: 961-967, 2016.

7. Matsumoto M, Nakajima W, Seike M, Gemma A and Tanaka N: Cisplatin-induced apoptosis in non-small-cell lung cancer cells is dependent on Bax- and Bak-induction pathway and synergistically activated by BH3-mimetic ABT-263 in p53 wild-type and mutant cells. Biochem Biophys Res Commun 473: 490-496, 2016.

8. Rocco G, Nason K, Brunelli A, Varela G, Waddell T and Jones DR: Management of stage IIIA (N2) non-small cell lung cancer: A transatlantic perspective. J Thorac Cardiovasc Surg 151: 1235-1238, 2016.

9. Parrillo L, Costa V, Raciti GA, Longo M, Spinelli R, Esposito R, Nigro C, Vastolo V, Desiderio A, Zatterale F, et al: Hoxa5 undergoes dynamic DNA methylation and transcriptional repression in the adipose tissue of mice exposed to high-fat diet. Int J Obes (Lond) 40: 929-937, 2016.

10. Morgan R and El-Tanani M: Hox genes as potential markers of circulating tumour cells. Curr Mol Med 16: 322-327, 2016.

11. Sandberg ES, Calikoglu AS, Loechner KJ and Snyder LL: Short stature homeobox-containing haploinsufficiency in seven siblings with short stature. Case Rep Endocrinol 2017: 7287351, 2017.

12. Catela C, Shin MM, Lee DH, Liu JP and Dasen JS: Hox proteins coordinate motor neuron differentiation and connectivity programs through ret/gfralpha genes. Cell Rep 14: 1901-1915, 2016.

13. Krumlauf R: Hox genes and the hindbrain: A study in segments. Curr Top Dev Biol 116: 581-596, 2016.

14. Zhong Z, Shan M, Wang J, Liu T, Xia B, Niu M, Ren Y and Pang D: HOXD13 methylation status is a prognostic indicator in breast cancer. Int J Clin Exp Pathol 8: 10716-10724, 2015.
15. Aquino G, Franco R, Sabatino R, Mantia EL, Scognamiglio G, Collina F, Longo F, Ionna F, Losito NS, Liguori G, et al: Deregulation of paralogous 13 HOX genes in oral squamous cell carcinoma. Am J Cancer Res 5: 3042-3055, 2015.

16. DiCicco-Bloom E, Lord C, Zwaigenbaum L, Courchesne E, Dager SR, Schmitz C, Schultz RT, Crawley J and Young LJ: The developmental neurobiology of aut-ism spectrum disorder. J Neurosci 26: 6897-6906, 2006.

17. Ranzi AD, da Silva JN, Graziottin TM, Annels N and Bica CG: Immunohistochemistry biomarkers in nonmuscle invasive bladder cancer. Appl Immunohistochem Mol Morphol 25: 178-183, 2017.

18. McGrath SE, Michael A, Morgan R and Pandha H: EN2 in prostate cancer. Adv Clin Chem 71: 47-76, 2015.

19. Kaur H, Sehgal IS, Bal A, Gupta N, Behera D, Das A and Singh N: Evolving epidemiology of lung cancer in India: Reducing non-small cell lung cancer-not otherwise specified and quantifying tobacco smoke exposure are the key. Indian J Cancer 54: 285-290, 2017

20. Cepollaro S, Della Bella E, de Biase D, Visani M and Fini M: Evaluation of RNA from human trabecular bone and identification of stable reference genes. J Cell Physiol 233: 4401-4407, 2018.

21. Livak KJ and Schmittgen TD: Analysis of relative gene expression data using real-time quantitative PCR and the 2-(Delta Delta C(T)) method. Methods 25: 402-408, 2001.

22. Omi M, Harada H, Watanabe Y, Funahashi J and Nakamura H: Role of En2 in the tectal laminar formation of chick embryos. Development 141: 2131-2138, 2014.

23. Martin NL, Saba-El-Leil MK, Sadekova S, Meloche S and Sauvageau G: EN2 is a candidate oncogene in human breast cancer. Oncogene 24: 6890-6901, 2005.

24. Bose SK, Bullard RS and Donald CD: Oncogenic role of engrailed-2 (en-2) in prostate cancer cell growth and survival. Transl Oncogenomics 3: 37-43, 2008.

25. Morgan R, Bryan RT, Javed S, Launchbury F, Zeegers MP, Cheng KK, James ND, Wallace DM, Hurst CD, Ward DG, et al: Expression of Engrailed-2 (EN2) protein in bladder cancer and its potential utility as a urinary diagnostic biomarker. Eur J Cancer 49: 2214-2222, 2013.

26. Lai CY, Pan B, Luo Y, Liang WB, Chen J, Ye DM, Guo JN, Li L and Su ZX: Engrailed-2 is down-regulated but also ectopically expressed in clear cell renal cell carcinoma. Mol Biol Rep 41: 3651-3657, 2014

27. Xu W, Banerji S, Davie JR, Kassie F, Yee D and Kratzke R: Yin yang gene expression ratio signature for lung cancer prognosis. PLoS One 8: e68742, 2013.

28. Togel L, Nightingale R, Chueh AC, Jayachandran A, Tran H, Phesse T, Wu R, Sieber OM, Arango D, Dhillon AS, et al: Dual targeting of bromodomain and extra-terminal domain proteins, and WNT or MAPK signaling, inhibits c-MYC expression and proliferation of colorectal cancer cells. Mol Cancer Ther 15: 1217-1226, 2016

29. Sempou E, Biasini E, Pinzon-Olejua A, Harris DA and Malaga-Trillo E: Activation of zebrafish Src family kinases by the prion protein is an amyloid- $\beta$-sensitive signal that prevents the endocytosis and degradation of E-cadherin/ $\beta$-catenin complexes in vivo. Mol Neurodegener 11: 18, 2016. 